\title{
O PSICÓLOGO NA MEDIAÇÃO POSITIVA PARA A DOAÇÃO DE ÓRGÃOS
}

\author{
Psychologist in the positive mediation for organ donation
}

Luiz Antônio da Silva

\section{RESUMO}

Objetivo: Este artigo tem por objetivo identificar na literatura o papel do psicólogo nas Comissões Intra-Hospitalares para Doação de Órgãos e Tecidos para Transplante (CIHDOTT), como fator associado ao florescimento, paz de espírito e acolhimento familiar no processo de captação e doação de órgãos. Materiais e Métodos: Revisão integrativa realizada com o objetivo de esclarecer a importância do papel do psicólogo no momento do processo da entrevista relativa à captação e doação de órgãos para transplante nas CIHDOTT. A análise dessa variável de pesquisa usou o critério de Oxford de evidência de publicação, em buscas com os descritores: Doação de Tecidos e Órgãos; Psicologia em Saúde; Resiliência Psicológica e Estudos de Intervenção, sem corte temporal para seleção. Foram localizados dez artigos nas bases de dados, discutidos por categorias de assunto. Resultados: Todas as publicações possuem baixo nível de evidência, mas oferecem grande contribuição na descrição do cenário de trabalho do psicólogo nas CIHDOTTs. Toda literatura considerada consta no intervalo de 2009 a 2015. Conclusão: Concluiu-se que o psicólogo é um agente facilitador do diálogo entre a família em luto e a decisão da doação de órgãos e tecidos entre seres humanos, um mediador importante que pode atuar na elaboração da dor do luto, com ênfase no florescimento, paz de espírito e acolhimento, antes, durante e depois do processo de captação e doação de órgãos para transplantes.

Descritores: Doação de Tecidos e Órgãos; Psicologia em Saúde; Resiliência Psicológica; Estudos de Intervenção.

Instituição:

Comissão Intra Hospitalar de Doação de Órgãos e Tecidos para Transplantes do HEAT-Hospital Estadual Alberto Torres, Rio de Janeiro/RJ

\section{Correspondência:}

Nome: Luiz Antônio da Silva

End.: Travessa João Sampaio, 79/Sobrado, CEP 24411-100, São Gonçalo/RJ

Tel.: (21) 2621-3781

E-mail: luizantoniopsicologo.ajuda@gmail.com

\section{INTRODUÇÃO}

Os primeiros transplantes de órgãos ocorreram no Brasil, na década de 1960, com pouca regulamentação e de modo descentralizado. Cada estado possuía suas filas e políticas de doação, com elevada taxa de morte, na espera pelo transplante. ${ }^{1}$

O Decreto $\mathrm{n}^{\circ} 2268 / 1997{ }^{2}$ regulamentou a Lei $\mathrm{n}^{\circ}$ 9394/1997 ${ }^{3}$ e criou o Sistema Nacional de Transplantes (SNT), uma rede nacional como diretriz para a captação de órgãos, com regulamentação e fila únicas. Atualmente, o cenário nacional da captação e doação de órgãos vem apontando resultados mais consistentes para a consolidação da doação, porém, trabalhos para melhorar o processo continuam, para mitigar as dificuldades ainda encaradas, envolvendo doador e receptor, bem como as equipes de implante e explante acerca da captação (objetivos ou subjetivos). Há uma logística truncada e as recusas de doação por fatores subjetivos são frequentes, em especial pelo baixo suporte às famílias dos doadores. Como a subjetividade da decisão campeia espaço em meio à necessidade objetiva do doar, a presença do Psicólogo 
assume papel de mediação e facilitação da decisão, elaborando informações e conduzindo o trato com o luto e acolhimento das famílias em perda. ${ }^{4}$

O pedido de doação de órgãos ocorre, pós-fechamento do protocolo de morte encefálica, momento de choque, e junto da constatação de falecimento. Embora seja um momento delicado, os efeitos das negativas são significativos: entre 1998 e 2012, cerca de 67,5 mil pessoas poderiam ter abandonado as filas de transplante, caso $80 \%$ dos familiares das 21.120 pessoas em condição de doação tivessem dito sim ao processo. ${ }^{5}$

O sucesso na captação de órgãos depende da rapidez na identificação e notificação de doadores potenciais e da capacidade clínica, mas, igualmente da aceitação familiar. Uma estimativa do Registro Brasileiro de Transplantes (RBT) indica que no Brasil há cerca de 30 doadores potenciais por milhão de brasileiros ao ano, mas que somente cerca de seis são efetivados, evidenciando a emergência da condição. ${ }^{6}$

Com isso, embora haja obrigação de notificação compulsória de doador potencial nas Unidades de Terapia Intensiva (UTI) ou Pronto-Socorro (PS), a estimativa é de que neste ano, 2015, 22 mil pessoas estejam na fila por um transplante no Brasil. ${ }^{7}$ Isso leva à consideração de que fatores internos subjetivos possam exercer significativa influência no baixo retorno de doadores, chamando a atenção para as alternativas de mediação. ${ }^{8}$

As Comissões Intra-Hospitalares de Doação de Órgãos e Tecidos para Transplantes (CIHDOTT) surgiram com o objetivo de melhorar a identificação dos potenciais doadores e oferecer suporte às famílias receptoras. A primeira CIHDOTT começou a funcionar no ano de 2005, apoiada pelas Portarias $n^{\circ} 1752 / 2005$ e $n^{\circ} 2600 / 2009$, em um hospital com 80 leitos e equipe multidisciplinar (coordenador médico, enfermeiro, assistente social e/ou psicólogo). ${ }^{4}$

A elaboração do luto pode levar de dias a anos e as dificuldades em doar podem ser minoradas com a intervenção proativa do Psicólogo no favorecimento da elaboração desse processo visando a positividade. ${ }^{9}$

Isso é feito pela mediação das informações, visando contribuir com a elaboração da aparente contradição da $M E$, com a visão de uma vida artificialmente mantida, o que gera esperanças de reversão. A atuação do Psicólogo oferece apoio e informação, conforme a capacidade da família do doador potencial, fazendo uma ponte entre ela e a equipe médica e entre a condição de luto e a necessidade de vida. ${ }^{10}$

Como parte do trabalho em captação de órgãos, o pesquisador - que é psicólogo - observou os resultados relacionados às dificuldades aparentes no que tange a elaboração do luto de cada família pela CIHDOTT do Hospital Estadual Alberto Torres (HEAT), de São Gonçalo, Rio de Janeiro. Nele, a equipe integra o psicólogo e oferece suporte aos familiares dos pacientes em ME, a fim de apoiar a doação e dar um desfecho positivo, com a quebra de paradigmas relacionados à morte.

O trabalho envolve uma interpretação positiva frente à tragédia vivenciada e, ao final do processo de doação, equipe e famílias realizam um ritual de partida, marcado pelo plantio de um jasmim branco. $O$ ato solene é realizado no Jardim do HEAT e integra famílias e profissionais em vínculos de apoio que elaboram a dor no processo de falecimento do ente querido.

É um trabalho sistemático com os sentidos de vida e morte, que permeiam as doações de órgãos e tecidos. $O$ projeto estimula a resiliência e solidariedade com a dor da perda, para além do objetivo de extração do órgão. Em momento posterior, as visitas ao local permitem à família reviver a memória boa da continuidade no jasmim branco que simboliza a permanência da vida.

Nos espaços entre o "eu" em perda de morte e o "outro" em esperança de vida, onde circula a decisão de doar, este trabalho orienta-se ao identificar o papel e os impactos da atuação do psicólogo nas CIHDOTT, com foco na melhoria dos índices de transplantes. $O$ profissional, nessa abordagem, é visto como um agente de ressignificações, em que pesa a exploração e o conhecimento de suas possibilidades de atuação na decisão de doar e no espelhamento para outras famílias acerca dessa decisão.

\section{OBJETIVO}

Verificar a importância do papel do psicólogo no processo de captação e doação de órgãos para transplantes, acolhimento familiar.

\section{MATERIAL E MÉTODOS}

A Revisão Integrativa (RI) é uma forma de estruturação de estudos que permite considerar estudos primários e secundários, com alta diferença metodológica e apresentações, a fim de responder ao interesse do estudo. Possibilita versatilidade para análise crítica de materiais que tenham natureza diversa, a fim de chegar a um produto final crítico e integrado. ${ }^{11}$

As dimensões que envolvem o gerenciamento acerca das subjetividades no que tange o processo de captação de órgãos, a comparação de intervenção 
padrão (comparativo com as práticas utilizadas ou não utilizadas) e Outcomes/desfechos (PICO) serviram como orientação para a construção da questão de pesquisa: "A importância do papel do psicólogo em CIHDOTT e suas possibilidades quanto a uma psicologia positiva no apoio às famílias doadoras". Com essa consideração ampla dos elementos envolvidos na pesquisa, foi possível identificar os principais fatores de contribuição para o florescimento, paz de espírito e acolhimento familiar na doação de órgãos, compreendendo as questões que se ligam à aceitação, não aceitação e mediação do processo de doar na visão da literatura, recuperando a pergunta de pesquisa com base em retornos ajustados aos seus interesses. ${ }^{12,13}$

A fim de uma classificação do material obtido na proposição de estudo, no "Nível de Evidência Científica por Tipo de Estudo", do Oxford Centre for EvidenceBased Medicine, ${ }^{14}$ os tipos de estudo recebem as seguintes classificações: a) grau de recomendação $A$ : $1 \mathrm{~A}$, revisão sistemática de ensaios clínicos controlados, $1 \mathrm{~B}$, ensaio clínico controlado e randomizado de intervalo de confiança estreito e $1 \mathrm{C}$, resultados terapêuticos do tipo tudo ou nada; b) grau de recomendação B: $2 A$ revisão sistemática de estudos de corte, $2 \mathrm{~B}$ estudos de corte, $2 \mathrm{C}$ observação de resultados terapêuticos $\mathrm{e}$ estudo ecológico; $3 \mathrm{~A}$ revisão sistemática de estudos de caso-controle; 3B estudos de caso-controle; c) grau de recomendação C: quatro relatos de caso e d) grau de recomendação $\mathrm{D}$ : cinco relatos de caso de menor qualidade.

Os critérios de inclusão no estudo foram: abordagem da participação do Psicólogo em CIHDOTT, resultados objetivos ou descritivos dessa presença e relatos de medidas ou intervenções associadas à presença do Psicólogo nessas comissões, considerando em publicações nacionais e internacionais relacionadas à produção de conhecimento em saúde, com metodologia de revisão de literatura e apresentação de resultados apresentada de modo claro, conciso e coerente, bem como realizada de acordo com o método apresentado. Não houve limitação de ano de produção ou de idiomas, sendo considerada a pertinência temática da produção para a inserção.

Foram descartados para uso na pesquisa artigos que não apresentavam resultados qualitativos ou quantitativos da presença do psicólogo nas CIHDOTT, que se mostraram incompletos na descrição dos pontos principais de ação, intervenção ou possibilidade de atuação profissional ou cuja metodologia não se mostrou suficientemente clara ou coerente. Da mesma forma, foram descartados estudos localizados duplamente nas bases de pesquisa consideradas ou que apresentassem abordagem parcial a respeito do papel desse profissional na multidisciplinaridade dessas comissões.

Os dados foram apresentados seguindo o encadeamento temático, ou seja, na descrição do papel do psicólogo e de suas possibilidades dentro das CIHDOTT conforme a organização textual, sem privilégio de ano ou autor.

A busca dos artigos ocorreu com a utilização dos seguintes Descritores em Ciências da Saúde (DeCs): Doação de Tecidos e Órgãos; Psicologia em Saúde; Resiliência Psicológica e Estudos de Intervenção, utilizados em conjunto ou separados, a fim de levantar uma base suficiente para a avaliação crítica dentro dos critérios de inclusão e de exclusão. Foram consultadas as bases: Diretório de Políticas de Acesso Aberto das Revistas Científicas Brasileiras IBICT (Diadorim); Blucher Proceedings; Scientific Electronic Library Onlyne (SciELO), SciELO Public Health, Biblioteca Virtual em Saúde (BVS) e Periódicos Eletrônicos em Psicologia (Pepsic).

Os artigos obtidos foram lidos inicialmente em títulos e resumos, em busca da adequação proposta nos critérios de aceitação ou recusa para o estudo e os que passaram nessa primeira filtragem tiveram leitura integral. Foram descartados os artigos que, em sua leitura integral, apresentaram alterações ou inconformidades metodológicas, verificáveis apenas em etapa mais avançada de consideração. Após a leitura integral e organização do conteúdo em planilha do Microsoft Excel® e resumo sintático em documento de texto no programa Microsoft Word $\circledast$, os estudos foram divididos por seu método, classificação e avaliação do nível de evidência, do impacto da publicação e pela síntese do teor de seus resultados. Ao final dessa composição seletiva, a colcha teórica do estudo formou-se dividida por classes e resultados que compuseram o estado-daarte do objetivo de pesquisa de modo descritivo.

\section{RESULTADOS}

A coleta inicial de pesquisa com os descritores totalizou 79 artigos que, após a análise oferecida por seus resumos/abstracts e títulos, foram filtrados para o total de 22 publicações. Estas, após leitura integral e confrontamento metodológico, resultaram em oito artigos que responderam aos critérios de inclusão, propostos com suficiência de retorno aos objetivos do estudo, abordando de forma suficiente os impactos, ou algum prisma de impactos da presença do psicólogo no espaço das CIHDOTT, conforme descrito na Tabela abaixo: 
Tabela 1 - Descrição dos estudos incluídos na revisão integrativa, segundo autor (es), periódicos, base de dados e ano de publicação. São Paulo, 2015.

\begin{tabular}{|c|c|c|c|c|c|c|c|}
\hline $\begin{array}{c}\mathbf{N} \\
\text { chamada }\end{array}$ & Autor(es) & Metodologia & Atuação do psicólogo nas CIHDOTT & $\begin{array}{l}\text { Nível } \\
\text { de } \\
\text { Evid. }\end{array}$ & Periódico & $\begin{array}{l}\text { Base de dados } \\
\text { de coleta }\end{array}$ & Ano \\
\hline 5 & $\begin{array}{l}\text { Pessoa JLE, } \\
\text { Schirmer J, } \\
\text { Aguiar Roza B. }\end{array}$ & $\begin{array}{l}\text { Estudo } \\
\text { transversal } \\
\text { correlacional }\end{array}$ & $\begin{array}{l}\text { Parte do fator humano envolvido no processo da } \\
\text { doação é um fator determinante como agente } \\
\text { facilitador da tomada de decisão da família }\end{array}$ & C & Acta Paul Enferm & SciElO Brasil & 2013 \\
\hline 12 & $\begin{array}{l}\text { Silva VFA, } \\
\text { Rocha JR }\end{array}$ & $\begin{array}{l}\text { Revisão de } \\
\text { literatura sem } \\
\text { sistematização }\end{array}$ & $\begin{array}{l}\text { O atendimento psicológico não só trabalha o } \\
\text { paciente como também os familiares, uma vez } \\
\text { que os mesmos são de extrema importância para } \\
\text { o processo de saúde e doença no decorrer do } \\
\text { transplante, fazendo com que o trabalho da equipe } \\
\text { de saúde possa resultar em boas conclusões. }\end{array}$ & D & $\begin{array}{l}\text { Caderno de Graduação- } \\
\text { Ciências Biológicas e da } \\
\text { Saúde }\end{array}$ & $\begin{array}{l}\text { Grupo } \\
\text { Tiradentes } \\
\text { Portal de } \\
\text { Periódicos }\end{array}$ & 2014 \\
\hline 13 & $\begin{array}{l}\text { Leite LLEC, } \\
\text { Corrêa SS. }\end{array}$ & $\begin{array}{l}\text { Relato de caso / } \\
\text { experiência }\end{array}$ & $\begin{array}{l}\text { O papel do psicólogo, utilizando da subjetividade } \\
\text { no acolhimento e na escuta oferecendo suporte } \\
\text { psicológico auxilia nesse processo. }\end{array}$ & 4 & $\begin{array}{l}\text { Blucher Medical } \\
\text { Proceedings }\end{array}$ & $\begin{array}{l}\text { Blucher } \\
\text { Proceedings }\end{array}$ & 2014 \\
\hline 15 & $\begin{array}{l}\text { Santos LJL; } \\
\text { Vieira MJ. }\end{array}$ & $\begin{array}{l}\text { Observação } \\
\text { de resultados } \\
\text { terapêuticos }\end{array}$ & & $2 c$ & $\begin{array}{l}\text { Revista Ciência \& Saúde } \\
\text { Coletiva }\end{array}$ & Scielo Brasil & 2012 \\
\hline 16 & $\begin{array}{l}\text { Coelho CBO, } \\
\text { Silva DS. }\end{array}$ & $\begin{array}{l}\text { Revisão de } \\
\text { literatura sem } \\
\text { sistematização }\end{array}$ & $\begin{array}{l}\text { Acolhimento e abordagem familiar, e nos aspectos } \\
\text { subjetivos do processo }\end{array}$ & 5 & JBT & BVS & 2012 \\
\hline 17 & $\begin{array}{l}\text { Scremin SM, Ávila } \\
\text { RCD, Branco CJ }\end{array}$ & $\begin{array}{l}\text { Relato de caso / } \\
\text { experiência }\end{array}$ & Minimização do sofrimento & 4 & Revista da SBPH & Pepsic & 2009 \\
\hline 18 & $\begin{array}{l}\text { Martins CM, } \\
\text { Cosmo M }\end{array}$ & $\begin{array}{l}\text { Revisão de } \\
\text { literatura sem } \\
\text { sistematização }\end{array}$ & $\begin{array}{l}\text { Ajudar nesse processo de abordagem da família } \\
\text { pela equipe de saúde, facilitando o manejo de } \\
\text { possíveis dificuldades e mecanismos suscitados } \\
\text { pela perda inesperada }\end{array}$ & 5 & JBT & Diaodorim & 2009 \\
\hline 18 & $\begin{array}{l}\text { Santos LDJ, } \\
\text { Vieira MJ }\end{array}$ & $\begin{array}{l}\text { Relato de caso / } \\
\text { experiência }\end{array}$ & $\begin{array}{l}\text { Buscar alternativas e estratégias de superação } \\
\text { frente a impasses e dificuldades }\end{array}$ & 4 & $\begin{array}{l}\text { Ciência \& Saúde } \\
\text { Coletiva }\end{array}$ & $\begin{array}{l}\text { Scielo Public } \\
\text { Healtrh }\end{array}$ & 2012 \\
\hline 20 & $\begin{array}{l}\text { Nogueira MAM, } \\
\text { Leite CRA, } \\
\text { Reis Filho EV, } \\
\text { Medeiros LM }\end{array}$ & $\begin{array}{l}\text { Observação } \\
\text { de resultados } \\
\text { terapêuticos }\end{array}$ & & $2 c$ & $\begin{array}{l}\text { Recien - Revista } \\
\text { Científica de } \\
\text { Enfermagem }\end{array}$ & BVS & 2015 \\
\hline 20 & $\begin{array}{l}\text { Arcanjo RA, } \\
\text { Oliveira LCD, } \\
\text { Silva DDD. }\end{array}$ & $\begin{array}{l}\text { Revisão de } \\
\text { literatura sem } \\
\text { sistematização }\end{array}$ & $\begin{array}{l}\text { Integrar equipe multidisciplinar oferecendo suporte } \\
\text { para a família }\end{array}$ & 5 & Revista Bioética & Scielo Brasil & 2013 \\
\hline
\end{tabular}

Quanto ao ano de publicação, a totalidade dos artigos está situada entre os anos de 2009-2015. A amostra foi composta por materiais oriundos das bases Scielo Brasil, Grupo Tiradentes Portal de Periódicos, BVS, Scielo Public Health, Diadorim, Pepsic e Blusher Proceedings. Há baixa classificação de evidência, em razão da natureza dessas pesquisas, que em geral são relatos de experiências ou revisões que não se baseiam em estudos de corte, mas que ao seu modo subsidiam a formação crítica do terreno de estudo.

Dois artigos 5,15 mencionam o papel do psicólogo como parte da equipe multidisciplinar e fator humano de potencial resultado positivo para a facilitação do processo de doação; um artigo ${ }^{12}$ como elemento de suporte nos processos de saúde e doença como facilitador de bons desfechos (no caso, doação); dois, ${ }^{13,16}$ como fator de escuta e trabalho com as subjetividades que podem impedir a aceitação da decisão de doar; um,,$^{17}$ como ator de minimização do sofrimento; dois, ${ }^{18,19}$ como fator de minimização de conflitos, impasses e dificuldades que possam ser levantadas entre familiares e, por fim, um, ${ }^{20}$ como elemento de suporte geral, tanto para as equipes quanto para os familiares.

\section{DISCUSSÃO}

Há poucos estudos com estrutura metodológica consistente que aborde, de maneira direta ou indireta, a participação do psicólogo nas CIHDOTT. O principal meio de difusão de conhecimento são estudos secundários.

A doação de órgãos é um tabu por apropriar-se do corpo de uma pessoa (doador), a fim de satisfazer projetos de vida que pertencem a outra (receptor). ${ }^{5}$ Nesse choque, o Psicólogo atua em busca de mediações da dor e do 
sofrimento para familiares e indivíduos que vivenciam a decisão doadora, a fim de que tenham boa visão desta, doando ou não, com amparo, acolhimento e suporte..$^{12}$ Apoia os familiares envolvidos na decisão de doar, sim ou não, em um momento de luto e choque, auxiliando na compreensão do diagnóstico e dando informações positivas e acessíveis sobre o processo. ${ }^{13}$

Soma esforços à equipe hospitalar e oferece aos familiares condições para que tenham menores sequelas emocionais, possibilitando uma visão positiva a seu respeito, com resiliência e elaboração. $O$ trabalho do psicólogo minimiza o sofrimento da perda para os familiares e cria um cenário mais favorável à humanização do atendimento, por possibilitar maior envolvimento e aproximação com a realidade de cada familiar e suas subjetividades, posicionando o processo de doação como via de mão-dupla, em que também importa a qualidade de vida e situação geral de quem opta por doar. ${ }^{15}$

O papel do psicólogo nas CIHDOTT é o de mediar, orientar, dar suporte e criar canais de decisão entre o luto e a doação, usando seus conhecimentos e saberes plurais, a fim de uma prática mais eficiente. É uma vivência mediada e orientada pelo acolhimento, eixo central do seu trabalho.

\section{CONCLUSÃO}

O papel do psicólogo nas CIHDOTT é focalizado nos seguintes pontos: agente integrante e ativo das comissões multidisciplinares; importante fator humano para a mediação da decisão de doação de órgãos e para a elaboração familiar da dor e do sofrimento da perda de seu ente querido, que resulta no consentimento familiar para doação de órgãos, a fim de que o processo tenha um bom desfecho; profissional apto e habilitado para trabalhar nas subjetividades e abordagens necessárias aos familiares na vivência do processo de luto e de perda, a fim de chegar a uma conclusão favorável do processo - com percepção positiva do ato, doando ou não. Por fim, o profissional pode ter ainda o papel de ser um gerenciador e mediador de conflitos, dores e sofrimentos, trazendo melhor perpasse psicológico ao processo. Ainda concluindo, este trabalho pode servir para outras propostas de novas pesquisas, que apontam indubitavelmente o oficio do psicólogo, construindo outros instrumentos de apoio, não só aos familiares doadores, mas aos profissionais envolvidos no processo de captação para doação de órgãos para transplantes.

\section{ABSTRACT}

Purpose: This article aim to identify in the literature the role of the psychologist in the Intra-Hospital Committees of the Organ and Tissue donation for Transplantation (CIHDOTTs), as an associated factor to the booming, peace of mind, and foster care in the organs procurement and donation process. Materials and Methods: Integrative review performed with the purpose to clarify the importance of the role of the psychologist in the interviewing process related to the organ procurement and donation for transplantation in the CIHDOTTs. The analysis of such research variable used the Oxford publishing evidence criterion, searching the describers: Organ and Tissue Donation; Psychology in Health; Psychological Resilience, and Studies in Intervention without temporal cut in the selection. Ten articles were located on the database, discussed by category of subject. Results: All the publications have a low evidence level, but they offer a major contribution to describe the working scenario of the psychologist in the CIHDOTTs. The literature was considered within the 2009 to 2015 interval. Conclusion: It was concluded that the psychologist is a facilitating agent in the dialogue between the bereaved family and the decision to donate organs and tissues between human beings, an important mediator, who can actuate in the preparation for the mourning pain, emphasizing the flourishing, peace of mind and foster care before, during and after the organ procurement and donation process for transplantation.

Keywords: Tissue and Organ Procurement; Health Psychology; Resilience, Psychological; Intervention Studies. 


\section{REFERÊNCIAS}

1. Pedra ASA, Moraes DP. A Criação de microrregiões como critério preponderante na fila única de transplante de órgãos: uma proposta de participação popular por aproximação. Revista de Direito Sanitário, 2011;11(3):15573.

2. Brasil. Decreto n. 2.268, de 30 de junho de 1997. Regulamenta a Lei $n^{\circ} 9.434$, de 4 de fevereiro de 1997, que dispõe sobre a remoção de órgãos, tecidos e partes do corpo humano para fim de transplante e tratamento, e dá outras providências. Disponível em: http://www.lexml.gov. br/urn/ur n:lex:br:federal:decreto:1997-06-30;2268.

3. Brasil. Lei n. 9434, de 4 de fevereiro de 1997. Dispõe sobre a remoção de órgãos, tecidos e partes do corpo humano para fins de transplante e tratamento e dá outras providências. Disponível em: http://www.planalto.gov.br/ ccivil_03/LEIS/L9434.htm.

4. Roza B, Odiema M, Glezer M, Sá J, Knobel E. Captação de órgãos para transplante. 2006. In: Knobel E. Condutas no paciente grave. São Paulo: Atheneu, 1753-64.

5. Pessoa JLE, Schirmer J, Aguiar Roza B. Avaliação das causas de recusa familiar a doação de órgãos e tecidos. Acta Paul Enferm. 2013;26(4):323-30.

6. Moraes ELD, Massarolo MCKB. 2009. Recusa de doação de órgãos e tecidos para transplante relatados por familiares de potenciais doadores. Acta Paul Enferm, 2009;22(2):131-5.

7. Cerqueira R. O Globo. Cai número de doadores e 22 mil pacientes aguardam um transplante. Ed. 12.05.2015. Disponível em: http://g1.globo.com/hora1/noticia/2015/05/ cai-o-numero-de-doadores-e-22-mil-pacientes-aguardamum-transplante.html.

8. Mattia ALD, Rocha ADM, Freitas-Filho JPAD, Barbosa MH, Rodrigues MB, Oliveira MGD. Análise das dificuldades no processo de doação de órgãos: uma revisão integrativa da literatura. Bioethikos. 2010;4(1):66-74.

9. Meyerowitz BE. Psychosocial correlates of breast cancer and its treatments. Psychological Bulletin. 2008;87(1):108.
10. Coelho CBO, Silva DS. Considerações da psicologia hospitalar sobre a entrevista familiar na doação de órgãos e tecidos. JBT. 2012;15(4):1703.

11. Torraco RJ. Writing integrative literature reviews: Guidelines and examples. Human Resource Development Review. 2005;4(3):356-67.

12. Silva VFA, Rocha JR. Atuação do psicólogo junto a equipe de saúde em unidades de transplantes. Caderno de Graduação-Ciências Biológicas e da Saúde-FITS. 2014;2(2):153-64.

13. Leite LLEC, Corrêa SS. Reflexões sobre o trabalho do psicólogo no processo de doação de órgãos. Blucher Medical Proceedings. 2014;1(6),22-5.

14. Phillips B, Ball C, Sackett D, Badenoch D, Straus S, Haynes B, et al. Oxford centre for evidence-based medicine levels of evidence. Verfügbar unter: http://www cebm net/ levels_of_evidence asp. 2001.

15. Arcanjo RA, Oliveira LCD, Silva DDD. Reflections about intra-hospital commission about organs and tissues donation for transplants. Revista Bioética. 2013;21(1):119-25.

16. Coelho CBO, Silva DS. Considerações da psicologia hospitalar sobre a entrevista familiar na doação de órgãos e tecidos. JBT. 2012;15(4):1703.

17. Scremin SM, Ávila RCD, Branco CJ. Alcance e limites do serviço de psicologia do hospital de pronto socorro de Canoas-deputado Nelson Marchezan. Revista da SBPH, 2009;12(1):57-69.

18. Martins $\mathrm{CM}$, Cosmo M. A centralidade da família no processo de doação de órgãos e tecidos. JBT. 2009;12(4):1186-90

19. Santos LDJ, Vieira MJ. The role of the psychologist in hospitals and maternity wards in the state of Sergipe. Ciência \& Saúde Coletiva. 2012;17(5):1191-202.

20. Arcanjo RA, Oliveira LCD, Silva DDD. Reflections about intra-hospital commission about organs and tissues donation for transplants. Revista Bioética. 2013;21(1):119-25. 